\title{
Impact of Early Childhood Caries on Oral Health-related Quality of Life Among 4-6-year-old Children Attending Delhi Schools: A Cross-sectional Study
}

\author{
Amrita Jaggi ${ }^{1}$, Charu M Marya ${ }^{2}$, Ruchi Nagpal ${ }^{3}$, Sukhvinder S Oberoi ${ }^{4}$, Sakshi Kataria ${ }^{5}$, Pratibha Taneja ${ }^{6}$
}

\begin{abstract}
Introduction: Oral diseases like early childhood caries (ECC), trauma, teething pain, and eruption disturbances are widely prevalent among the 4-6-year subgroup of population and are considered a public health problem worldwide.

Aim: To assess the impact of ECC on oral health-related quality of life (OHRQoL) among 4-6-year-old children attending schools in Delhi.

Materials and methods: A cross-sectional epidemiological study was carried out to assess the impact of ECC on OHRQoL among 4-6-year old children. Data were collected by a combination of the structured questionnaire of sociodemographic details and early childhood oral health impact scale (ECOHIS). The clinical examination was conducted for the assessment of dentition status and pufa index according to WHO criteria 2013. Statistical analysis was performed using the Chi-square test, the Kruskal-Wallis test, and the Mann-Whitney $U$ test.

Results: The prevalence of ECC was found to be $20 \%$ among preschoolers which was lower among younger children and increased with age. The ECOHIS responses reported that items related to pain, irritation, difficulty in eating some foods, and difficulty to drink hot or cold beverages, felt guilty, feeling of frustration, and been upset were the most frequent on the child impact section (CIS).

Keywords: Early childhood caries, Early childhood oral health impact scale, Oral health-related quality of life.

International Journal of Clinical Pediatric Dentistry (2019): 10.5005/jp-journals-10005-1626
\end{abstract}

\section{INTRODUCTION}

Oral health is related to general health and quality of life, which emphasizes the importance of retaining good functional dentition. ${ }^{1}$ A healthy mouth enables not only nutrition of the physical body but also enhances social interaction and promotes self-esteem and feelings of well-being. Oral health affects people physically and psychologically. Good oral health during infancy and childhood is also important for the overall health and well-being of a child, and is one of the building blocks for a disease-free life. ${ }^{2}$ Oral diseases like ECC, trauma, teething pain, and eruption disturbances are widely prevalent among the 4-6-year subgroup of population and are considered a public health problem worldwide. ${ }^{3}$ ECC has also been described as a social, political, behavioral, medical, psychological, economical, and dental problem, because it is epidemic in disadvantaged children, regardless of race, ethnicity, or culture. A long-term follow-up reveals that children who experience ECC are more likely to develop dental problems as they grow older and the prevalence rate ranges from 1 to $12 \%$ in preschoolers of developed countries and from 50 to $80 \%$ in high-risk groups. ${ }^{4}$ ECC can have a significant negative impact on the life of children. Research has shown that the most common difficulties experienced by children as a result of ECC are the ability to chew, difficulty in drinking hot or cold beverages, sleeping, school performances, socializing, irritation, as well as growth and height. ${ }^{5}$

The concept of OHRQoL relates to the impact which oral health or disease has on the individual's daily functioning, wellbeing, or quality of life. ${ }^{8}$ Measures of OHRQoL have been used as a complement to the assessment of treatment needs in oral health, as well as in the prioritization of care and for evaluating the outcomes of treatment strategies. In recent years, there has been a growing emphasis on the assessment of the impact of oral conditions
${ }^{1-6}$ Department of Public Health Dentistry, Sudha Rustagi College of Dental Sciences and Research, Faridabad, Haryana, India

Corresponding Author: Amrita Jaggi, Department of Public Health Dentistry, Sudha Rustagi College of Dental Sciences and Research, Faridabad, Haryana, India, Phone: +91 9999681066, e-mail: amritakaur456@gmail.com

How to cite this article: Jaggi A, Marya CM, et al. Impact of Early Childhood Caries on Oral Health-related Quality of Life Among 4-6-year-old Children Attending Delhi Schools: A Cross-sectional Study. Int J Clin Pediatr Dent 2019;12(3):215-221.

Source of support: Nil

Conflict of interest: None

on the quality of life of preschool children. Various instruments measure the quality of life related to oral health, most of them have been developed initially for adults or elderly. Later, instruments were developed to measure OHRQoL among children, one such instrument is the ECOHIS, which is administered to parents/ caretakers of preschool children to assess their (preschooler's) ${ }^{6}$

\section{OHRQoL}

Thus, the present study was planned to assess the prevalence, impact, and severity of ECC on OHRQoL among 4-6 years children attending schools of Delhi.

\section{Materials and Methods}

This cross-sectional epidemiological study was carried out to assess the impact of ECC on OHRQoL among 4-6-year old children attending Delhi schools. Ethical clearance was sought from the Institutional Ethical Committee of "Sudha Rustagi College of Dental Sciences and Research," Faridabad. 


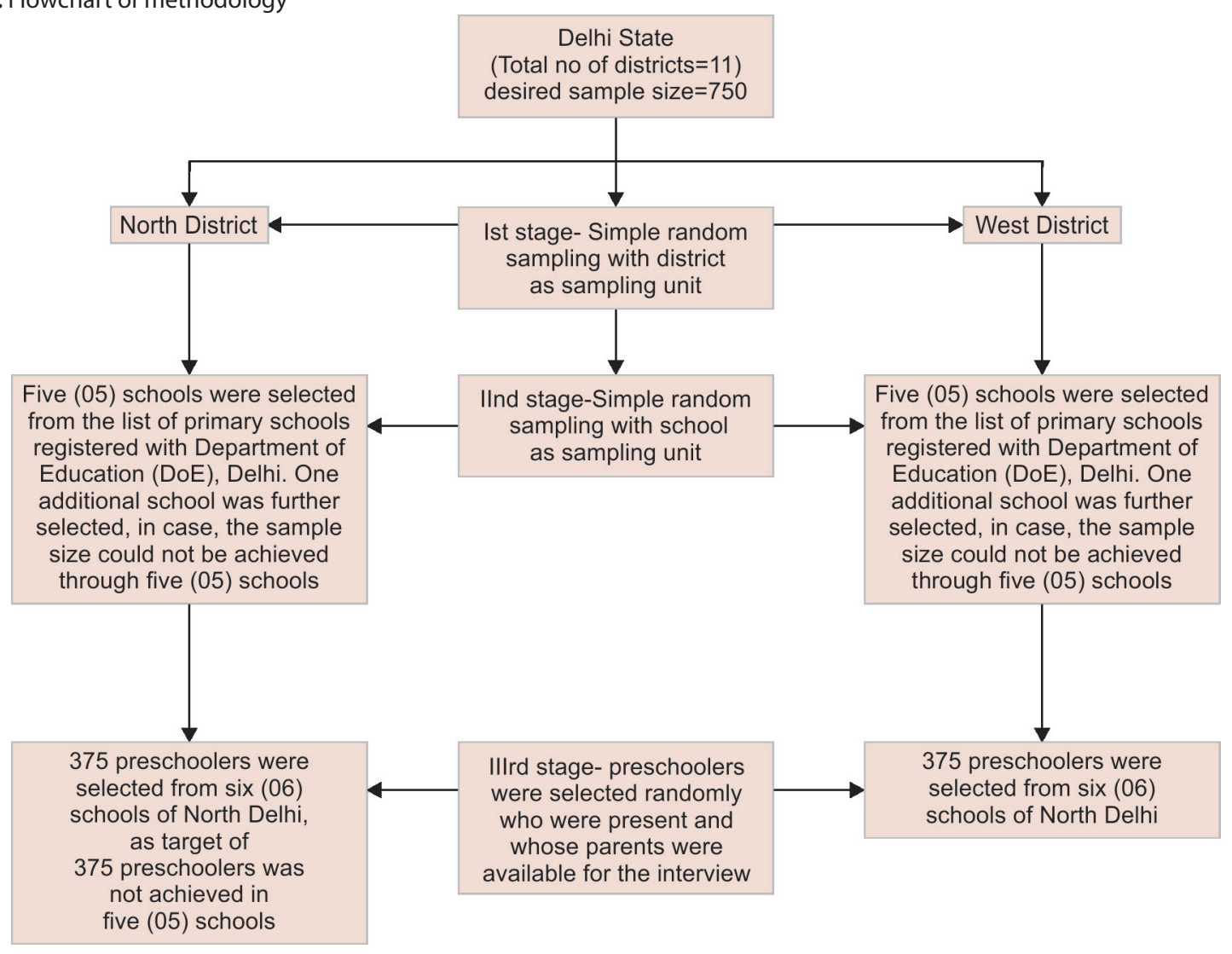

An information sheet was provided to each subject before taking informed consent from them prior to the questionnaire administration and clinical examination.

A formula was used for sample size estimation to determine the difference between two proportions. The proportion of the ECC-free children having an impact on OHRQoL was $32 \%$. A sample of 750 preschoolers was procured using the multistage cluster sampling technique with schools as the sampling unit (Flowchart 1). The proportion of children with ECC having an impact on OHRQoL was $51.2 \%$. The minimum sample size required for this study was calculated as 716 which was rounded off to 750 with the precision of $5 \%$.

\section{Training and Calibration}

The clinical examination of all the subjects was done by a single examiner. The examiner was trained under the guidance of a professional having previous experience in conducting such surveys to limit the intraexaminer variability. A pilot study was done prior to check the feasibility of the study.

\section{Inclusion and Exclusion Criteria}

Children of 4-6-year age attending schools in Delhi who were present on the day of examination with complete information given by their parents were included. Children whose parents did not give consent for clinical examination of the child, and whose children had major systemic diseases, craniofacial deformities, or syndromes, and who were not ready for clinical examination or were on long-term medications were excluded.

\section{Data Collection}

Data were collected by a combination of structured questionnaire and clinical examination was performed on their children. The questionnaire was composed of sociodemographic information and ECOHIS which is the only tool till the date available to measure OHRQoL of preschoolers.

\section{ECOHIS Questionnaire}

It is structurally composed of 13 items distributed between two sections: the CIS and family impact section (FIS). The CIS has four subscales: child symptom, child function, child psychology, and child self-image and social interaction. The FIS has two subscales: parental distress and family function. The scale has five rating response options to record how often an event has occurred in the life of a child: $0=$ never; $1=$ hardly ever; $2=$ occasionally; $3=$ often; $4=$ very often; $5=$ do not know. ECOHIS scores are calculated as a simple sum of the response codes for the CIS and FIS after recoding "Dont Know" responses as "missing." CIS and FIS ECOHIS scores range from 0 to 36 and 0 to 16, respectively, for which higher scores indicate a greater oral health impact and poorer OHRQoL.

The questionnaire was interviewer administered. Parents were interviewed during the parent-teacher meetings, prescheduled in the school. Children's parents/guardians were asked questions related to their family income, occupation, educational status, family size, and oral hygiene habits of children. Parents were asked to answer the ECOHIS in an interview format. The questionnaire included ECOHIS items in both English and Hindi language as these two are the most commonly spoken languages in this part of India. ECOHIS was translated from English to Hindi by two Dental Public Health professionals fluent in both languages, i.e., Hindi and English. Then, it was back translated into English by two independent dentists. A group of dental professionals reviewed the Hindi version of ECOHIS questionnaire for appropriateness to culture. The Hindi version of ECOHIS was finally tested in a convenience sample of 
Impact of ECC on OHRQoL

caregivers of 66 preschoolers of Delhi. They were found to be able to answer the questions and had no problem in understanding any question or words in particular during the interview. The Hindi translation was found to be reliable in the overall study population (Cronbach's $\alpha=0.89$ ).

\section{Clinical Examination}

The clinical oral examination was conducted for the assessment of dentition status and pufa index. Apart from this, gingival bleeding, presence and extent of dental trauma, oral mucosal lesions, congenitally missing teeth, physiological tooth mobility, and eruption-associated inflammation were also recorded. Dentition status, gingival bleeding, presence, type, and location of oral mucosal lesions were recorded according to the criteria given by WHO Oral Health Survey-Basic Methods (2013). ${ }^{7}$ The pufa index for primary dentition was recorded as given by Monse et al. ${ }^{8}$

\section{Data Analysis}

Statistical analysis was conducted using the SPSS 21.0 version. Descriptive analysis (including frequency distribution) was performed for overall mean ECOHIS scores. The nonparametric Kruskal-Wallis and Mann-Whitney $U$ tests were used. The independent variables were characteristics of the child (gender and age), socioeconomic characteristics, and clinical oral conditions. The dependent variable was the total ECOHIS score. For the initial analyses, the sample was grouped into children free of caries, those with only lesions on incisors/canines, those with only lesions on molars, and those with lesions on both incisors/canines and molars. Comparisons were made among groups for each item on the ECOHIS.

\section{Results}

The study was conducted from 1 November 2016 to 15 May 2017. The survey was carried out in preschools of Delhi. A total of 750 school children which was composed of $55.9 \%$ females and $41.9 \%$ males with the maximum school children, i.e., $48.2 \%$ belonging to the 5 years age group. A majority of the children (64.5\%) brushed daily using toothpaste (97.10\%) in horizontal (93.2\%) directions. Table 1 depicts the demographic profile and oral hygiene profile of study population. Table 2 depicts the distribution of responses to the ECOHIS among the sample of parents from the populationbased survey. The items related to pain, irritation, difficulty eating and smiling, and missing preschool or day care were reported more frequently a CIS. Items related to taking time off from work, feeling guilty, and financial impact were recorded frequently of FIS of ECOHIS. About 7.9\% participants experienced dental pain or difficulty while drinking frequently. Whereas $\leq 3 \%$ participants had difficulty in eating, missed there preschool or were irritable, avoided talking, had been upset, or felt guilty. The response "Do not know" was excluded as none of the participants responded to this option. Table 3 provides the total impact on the ECOHIS score which was found to be more among subjects having caries only in posterior or both anterior and posterior teeth. Whereas significantly more impact was seen in the dental pain domain with subject having caries on both anterior and posterior teeth followed by caries only in posterior teeth when compared with caries-free subjects. For functional domain, psychological domain, parent distress domain, and family function domain, significantly more impact was seen among subjects having caries on both anterior and posterior teeth than the caries-free subjects. For self-image domain, significantly more impact was seen among subjects
Table 1: Demographic characteristics and oral hygiene habits

\begin{tabular}{lcc}
\hline Demographic characteristics & Frequency $(n)$ & Percentage \\
\hline Gender & 419 & $55.9 \%$ \\
Females & 331 & 44.1 \\
Males & & \\
Age & 291 & 38.8 \\
4 years & 362 & 48.2 \\
5 years & 97 & 12.9 \\
6 years & & \\
Brushing frequency & 484 & 64.5 \\
Once & 34 & 4.5 \\
Twice & 231 & 30.8 \\
Irregular & & \\
Material used for cleaning teeth & 728 & 97.10 \\
Toothpaste & 22 & 2.80 \\
Powder & & \\
Method of cleaning teeth & 34 & 4.8 \\
Vertical & 699 & 93.2 \\
Horizontal & 15 & 2.0 \\
Circular & & \\
\hline
\end{tabular}

Table 2: Frequency distribution of each ECOHIS items

\begin{tabular}{|c|c|c|c|}
\hline Items & & $\begin{array}{l}\text { Never/hardly } \\
\text { ever (1) }\end{array}$ & $\begin{array}{l}\text { Occasionally/ } \\
\text { often/very often }\end{array}$ \\
\hline \multirow[t]{2}{*}{ Total ECOHIS } & $N$ & 706 & 44 \\
\hline & $\%$ & 93.4 & 7.9 \\
\hline \multirow[t]{2}{*}{ Oral/dental pain } & $N$ & 727 & 23 \\
\hline & $\%$ & 97 & 3 \\
\hline \multirow[t]{2}{*}{ Difficulty drinking } & $N$ & 737 & 13 \\
\hline & $\%$ & 98.3 & 1.7 \\
\hline \multirow[t]{2}{*}{ Difficulty eating } & $N$ & 749 & 1 \\
\hline & $\%$ & 99.9 & 0.1 \\
\hline Difficulty pronouncing words & $N$ & 744 & 6 \\
\hline Missed preschool or school & $\%$ & 99.2 & 0.8 \\
\hline \multirow[t]{2}{*}{ Trouble sleeping } & $N$ & 740 & 10 \\
\hline & $\%$ & 98.6 & 1.3 \\
\hline \multirow[t]{2}{*}{ Irritable or frustrated } & $N$ & 741 & 9 \\
\hline & $\%$ & 98.8 & 1.2 \\
\hline \multirow[t]{2}{*}{ Avoided smiling or laughing } & $N$ & 749 & 1 \\
\hline & $\%$ & 99.8 & 0.1 \\
\hline \multirow[t]{2}{*}{ Avoided talking } & $N$ & 749 & 1 \\
\hline & $\%$ & 99.9 & 0.1 \\
\hline \multirow[t]{2}{*}{ Been upset } & $N$ & 728 & 22 \\
\hline & $\%$ & 97.1 & 3 \\
\hline \multirow[t]{2}{*}{ Felt guilty } & $N$ & 727 & 23 \\
\hline & $\%$ & 97 & 3.1 \\
\hline \multirow[t]{2}{*}{ Taken time off from work } & $N$ & 747 & 3 \\
\hline & $\%$ & 99.60 & 0.4 \\
\hline \multirow[t]{2}{*}{ Financial impact } & $N$ & 743 & 7 \\
\hline & $\%$ & 99.1 & 0.9 \\
\hline
\end{tabular}

having caries on both anterior and posterior than the caries only in posterior teeth. Table 4 displays the distribution of the means for each ECOHIS item in each domain and the overall ECOHIS score. On the CIS, the greatest mean impacts were recorded for items 
Impact of ECC on OHRQoL

Table 3: Location wise mean scores among children with and without caries.

\begin{tabular}{|c|c|c|c|c|c|c|c|c|}
\hline Dental caries & & Total ECOHIS & $\begin{array}{l}\text { Oral/dental } \\
\text { pain }\end{array}$ & $\begin{array}{l}\text { Function } \\
\text { domain }\end{array}$ & $\begin{array}{l}\text { Psychological } \\
\text { domain }\end{array}$ & Self-image & Parent distress & $\begin{array}{l}\text { Family } \\
\text { function }\end{array}$ \\
\hline (1) Caries free & Mean & 0.02 & 0.00 & 0.01 & 0.00 & 0.00 & 0.01 & 0.00 \\
\hline$(n=603)$ & SD & 0.53 & 0.08 & 0.16 & 0.04 & 0.00 & 0.24 & 0.00 \\
\hline (2) Caries only in anterior teeth & Mean & 0.91 & 0.45 & 0.45 & 0.00 & 0.00 & 0.00 & 0.00 \\
\hline$(n=11)$ & SD & 1.22 & 0.69 & 0.93 & 0.00 & 0.00 & 0.00 & 0.00 \\
\hline (3) Caries only in posterior teeth & Mean & 3.40 & 0.91 & 0.86 & 0.36 & 0.01 & 1.04 & 0.22 \\
\hline$(n=116)$ & SD & 6.23 & 1.24 & 1.96 & 1.19 & 0.09 & 2.21 & 0.87 \\
\hline $\begin{array}{l}\text { (4) Caries on both ant and post } \\
\text { teeth }\end{array}$ & Mean & 3.25 & 0.85 & 0.90 & 0.35 & 0.30 & 0.55 & 0.30 \\
\hline$(n=20)$ & SD & 6.58 & 1.18 & 2.05 & 1.35 & 1.34 & 1.57 & 0.73 \\
\hline Total & Mean & 0.64 & 0.17 & 0.17 & 0.07 & 0.01 & 0.18 & 0.04 \\
\hline$(n=750)$ & SD & 2.99 & 0.64 & 0.92 & 0.53 & 0.22 & 1.00 & 0.37 \\
\hline$p^{a}$ value & & $<0.001, \mathrm{~S}$ & $<0.001, \mathrm{~S}$ & $<0.001, \mathrm{~S}$ & $<0.001, \mathrm{~S}$ & $<0.001, \mathrm{~S}$ & $<0.001, \mathrm{~S}$ & $<0.001, \mathrm{~S}$ \\
\hline Post hoc pairwise comparison ${ }^{b}$ & & $3,4>1,2$ & $4>3>1,2$ & $3,4>1,2$ & $3,4>1,2$ & $4>1,2,3$ & $3>4>1,2$ & $3,4>1,2$ \\
\hline
\end{tabular}

${ }^{a}$ Kruskal-Wallis test

${ }^{b}$ Mann-Whitney $U$ test, S, statistically significant

Table 4: Relationship between severity of dental caries with overall ECOHIS and each item

\begin{tabular}{|c|c|c|c|c|c|c|c|c|}
\hline \multirow[b]{2}{*}{ Dental caries severity } & \multicolumn{2}{|c|}{ Caries free $(n=603)$} & \multicolumn{2}{|c|}{$\begin{array}{l}\text { Low severity dental caries } \\
(n=141)\end{array}$} & \multicolumn{2}{|c|}{$\begin{array}{l}\text { High severity dental } \\
\text { caries }(n=6)\end{array}$} & \multirow[b]{2}{*}{$p^{a}$-value } & \multirow[b]{2}{*}{ Post hoc ${ }^{b}$} \\
\hline & Mean & $S D$ & Mean & $S D$ & Mean & $S D$ & & \\
\hline Total ECOHIS & 0.02 & 0.53 & 2.75 & 5.72 & 13.50 & 4.68 & $<0.0001, \mathrm{~S}$ & $3>2>1$ \\
\hline Oral/dental pain & 0.00 & 0.08 & 0.77 & 1.12 & 3.17 & 0.75 & $<0.0001, \mathrm{~S}$ & $3>2>1$ \\
\hline Difficulty drinking & 0.00 & 0.08 & 0.35 & 0.79 & 2.17 & 0.41 & $<0.0001, \mathrm{~S}$ & $3>2>1$ \\
\hline Difficulty eating & 0.00 & 0.08 & 0.25 & 0.70 & 0.50 & 1.23 & $<0.0001, \mathrm{~S}$ & $3>2>1$ \\
\hline Difficulty pronouncing words & 0.00 & 0.00 & 0.04 & 0.29 & 0.00 & 0.00 & $<0.0001, \mathrm{~S}$ & $2>1$ \\
\hline Missed preschool or school & 0.00 & 0.00 & 0.11 & 0.53 & 0.33 & 0.82 & $<0.0001, \mathrm{~S}$ & $2,3>1$ \\
\hline Trouble sleeping & 0.00 & 0.00 & 0.16 & 0.62 & 0.33 & 0.82 & $<0.0001, \mathrm{~S}$ & $2,3>1$ \\
\hline Irritable or frustrated & 0.00 & 0.04 & 0.14 & 0.58 & 0.67 & 1.03 & $<0.0001, \mathrm{~S}$ & $3>2>1$ \\
\hline Avoided smiling or laughing & 0.00 & 0.00 & 0.03 & 0.27 & 0.00 & 0.00 & $0.01, \mathrm{~S}$ & $2>1$ \\
\hline Avoided talking & 0.00 & 0.00 & 0.02 & 0.25 & 0.00 & 0.00 & 0.12, NS & - \\
\hline Been upset & 0.00 & 0.12 & 0.34 & 0.90 & 3.00 & 0.00 & $<0.0001, \mathrm{~S}$ & $3>2>1$ \\
\hline Felt guilty & 0.00 & 0.12 & 0.34 & 0.93 & 3.00 & 0.00 & $<0.0001, \mathrm{~S}$ & $3>2>1$ \\
\hline Taken time off from work & 0.00 & 0.00 & 0.07 & 0.44 & 0.00 & 0.00 & $<0.0001, \mathrm{~S}$ & $2>1$ \\
\hline Financial impact & 0.00 & 0.00 & 0.13 & 0.52 & 0.33 & 0.82 & $<0.0001, \mathrm{~S}$ & $2,3>1$ \\
\hline
\end{tabular}

${ }^{a}$ Kruskal-Wallis test

${ }^{b}$ Mann-Whitney $U$ test; S, statistically significant; NS, statistically not significant

related to pain, irritability, and difficulty drinking. On the FIS, the most frequently reported items were felt guilty or been upset. The highest mean occurred as the group with high severity dental caries. Table 5 shows the association between pufa with each item of ECOHIS overall. The mean impact total ECOHIS score was found to be more among subjects in which pufa was present. A significant mean impact was reported for the item pain, difficulty in drinking, missed preschool, trouble sleeping, irritability, been upset, or felt guilty, though maximum impact was on items like pain, difficulty drinking, been upset, or felt guilty.

\section{Discussion}

Caries is a common, complex, chronic disease resulting from an imbalance of multiple risk factors and protective factors over time. ECC is a serious situation, because despite the fact that caries is not life threatening, the consequences of ECC include poor nutrition, pain, damage to permanent teeth, and potential risk to the child's overall well-being. Preschoolers affected by ECC tend to grow slower than caries-free children, may be underweight due to difficulty in eating and more likely to have dental problems as adults. ${ }^{9}$ There is now widespread consensus to include subjective oral health measure in the oral health needs assessments of various subgroups of the population. They reflect a move within dentistry toward a more holistic model of health, rather than a mechanistic view that sees the individual as existing independent of his or her environment. Further, this concept of OHRQoL falls within the domains of an "outcomes" model, which emphasizes consideration of people's self-reports in addition to the traditional disease and diagnosis the oriented "biomedical" model. ${ }^{10}$

For a long time, the perceptions of children of preschool age and younger have been neglected in the oral health epidemiological research area because of issues related to validity and reliability 
Impact of ECC on OHRQoL

Table 5: Association between pufa index with each item of ECOHIS

\begin{tabular}{lllllc}
\hline & \multicolumn{2}{l}{ Absent $(n=742)$} & \multicolumn{2}{c}{ Present $(n=8)$} & \\
\cline { 2 - 5 } Pufa index & Mean & SD & Mean & SD & \\
\hline Total ECOHIS & 0.47 & 2.35 & 16.38 & 9.33 & $<0.001, \mathrm{~S}$ \\
Oral/dental pain & 0.14 & 0.54 & 3.13 & 1.46 & $<0.001, \mathrm{~S}$ \\
Difficulty drinking & 0.06 & 0.33 & 2.38 & 1.06 & $<0.001, \mathrm{~S}$ \\
Difficulty eating & 0.04 & 0.26 & 1.75 & 1.49 & $<0.001, \mathrm{~S}$ \\
Difficulty pronouncing words & 0.01 & 0.13 & 0.00 & 0.00 & $0.835, \mathrm{NS}$ \\
Missed pre-school or school & 0.01 & 0.14 & 1.38 & 1.51 & $<0.001, \mathrm{~S}$ \\
Trouble sleeping & 0.02 & 0.20 & 1.50 & 1.31 & $<0.001, \mathrm{~S}$ \\
Irritable or frustrated & 0.02 & 0.20 & 1.50 & 1.31 & $<0.0001, \mathrm{~S}$ \\
Avoided smiling or laughing & 0.01 & 0.12 & 0.00 & 0.00 & $0.883, \mathrm{NS}$ \\
Avoided talking & 0.00 & 0.11 & 0.00 & 0.00 & $0.917, \mathrm{NS}$ \\
Been upset & 0.07 & 0.43 & 2.25 & 1.39 & $<0.001, \mathrm{~S}$ \\
Felt guilty & 0.07 & 0.44 & 2.25 & 1.39 & $<0.0001, \mathrm{~S}$ \\
Taken time off from work & 0.01 & 0.19 & 0.00 & 0.00 & $0.835, \mathrm{NS}$ \\
Financial impact & 0.03 & 0.23 & 0.25 & 0.71 & $0.013, \mathrm{~S}$ \\
\hline
\end{tabular}

Mann-Whitney $U$ test; $S$, statistically significant; NS, statistically not significant

as reported by Rebok et al. ${ }^{11}$ and Locker et al. ${ }^{12}$ However, the use of parent/caregiver assessments as proxy assessment of child OHRQoL is not ideally acceptable untill given the cognitive and linguistic issue of early childhood as reported by Cremeens et al., ${ }^{13}$ and Genderson et al. ${ }^{14}$

The ECOHIS was developed in the USA by Pahel et al. ${ }^{15}$ to assess the negative impact of oral disorders on quality of life among preschool children ( $0-5$ years of age). It is intended for use in epidemiological surveys to assess the burden of dental disease and its treatment among young children. It considers the child's entire lifetime experience of dental disease and treatment in parent's responses as reported by Albanto et al. ${ }^{16}$ In the current study, the translated Hindi version of ECOHIS was used which showed good reliability among the $4-6$ years subgroup. The internal consistency reliability of Hindi version of ECOHIS was successfully tested in the present study and Cronbach's alpha was found to be 0.72 which is good according to the standard of $>0.8$ thresholds set by most authors. This figure is comparable in magnitude with that reported by the other translated version of ECOHIS, i.e., French, ${ }^{17}$ Spanish. ${ }^{18}$ These above-mentioned versions have yielded Cronbach's alpha values ranging from 0.79 to 0.93 .

In the present study, the proportion of girls was more as compared with males in contrary to the prevalent male:female ratio in India. Although the differences were not statistically significant. This finding is in accordance with other studies conducted by Priyadarshini et al., ${ }^{19}$ where the proportion of females in the study was more.

A majority of the parents (fathers) of the study population were illiterate (42.3\%) followed by graduate or postgraduate $(17.1 \%)$, middle school (15.9\%), high school (13.3\%), and primary school $(11.5 \%)$. As reported in a study conducted in Bangalore by Singh et al., ${ }^{19}$ more than $70 \%$ of the parents were illiterates.

The prevalence of once daily brushing in the present study was found to be higher as compared with other studies conducted by Zhang et al. ${ }^{20}$ among Bulang preschoolers (37\%) among Rohtak preschoolers (42\%).

In the present study, the prevalence of ECC was found to be $20 \%$. This prevalence was lower than that found in Delhi state, i.e., $37.1 \%$ as found in National Oral Health Survey and Fluoride
Mapping, studies conducted by Simratvir et al. ${ }^{21}$ and Sudha et al. ${ }^{22}$ This is in accordance with studies conducted by Gopal et al. ${ }^{23}$ who found $27.3 \%$ of prevalence of ECC among preschoolers of Andhra Pradesh. In the present study, ECC prevalence was lower among younger children and increased with age. This finding was in accordance with the study conducted by Stephen et al. ${ }^{24}$ among Salem preschoolers. This is also in accordance with the studies carried out by Namal et al. ${ }^{25}$ This can be explained by the fact that dental caries is a cumulative process and develops over years. Thus, prevalence and severity of dental decay increased with age. The prevalence of pufa was $1.1 \%$ among the preschoolers of Delhi which was found to be very low. This is in contrast with the studies conducted by Monse et al. ${ }^{8}$ and Marya et al., ${ }^{26}$ in which there was a high prevalence of pufa scores, i.e., $84 \%$ and $25 \%$.

In the present study, the prevalence of caries was $20 \%$ among the preschoolers. Caries attack was more in the posterior teeth than in the anterior teeth. This may be due to the complex morphological nature of the posterior teeth. It is also evident that the sequence of caries attack follows a specific pattern: mandibular molars, maxillary molars, and maxillary anterior teeth were predominantly affected by caries, whereas the mandibular anterior teeth were least affected. This is similar to the caries pattern described by Chawla et al. ${ }^{27}$ for primary dentition.

In the present study, only $0.8 \%$ was found to have permanent restorations and $0.13 \%$ found to have secondary caries with permanent restorations. Disappointingly, however, is the observation that much of the dental caries experience relates to untreated decay.

Gingival bleeding, presence and extent of dental trauma, oral mucosal lesions, congenitally missing teeth, physiological tooth mobility and eruption associated inflammation factors were not found to significantly affect the OHRQoL of preschoolers. Thus, their findings have not been reported in the text.

The overall ECOHIS score in the present study was found to be 0.64 , which is much lower than that reported by Wong et al. ${ }^{28}$ among preschoolers of Hong Kong, i.e., 3.24, Martins et al. among Brazilian preschoolers was 2.95, and Albanto et al. ${ }^{16}$ among Diamantina (Brazil) preschoolers 8.25. The difference could be explained on the basis that the prevalence of ECC in these studies 
was much higher than that found in the present study. Apart from this, there could be one more probable reason. Despite the validation of Hindi version of ECOHIS in this Indian population, to assess the impact of oral health problem, it may be possible that the instrument was not developed sufficiently sensitive to detect OHRQoL in preschool children with a low prevalence of ECC. Neither overall ECOHIS nor any individual domain score showed any significant differences between females and males.

Individual domain of ECOHIS did not show any significant relationship with the age of the child except self-image and family function domains. In self-image domains, 4 years old and 5 years old subjects gave any score. According to child's developmental psychology, at the age of 6 is the beginning of the abstract thinking, self-image, and concept. Children start to compare their physical features and personality traits with those of other children. As the present study assessed children up to 6 years old only, that is why probably the reason for the low frequency of responses in this domain.

In the present study, most of the primary caregivers, i.e., 91.9-99.9\% reported that their child or family " never" experienced such problems. When compared with previous studies conducted by Wong et al. ${ }^{28}$ (85-98\%), Albanto et al. ${ }^{16}$ (79-97\%), and Pahel et al. ${ }^{15}$ (89-97\%). It was observed that the occurrence of "never" or "hardly ever" responses was commonly greater for all items in the ECOHIS instruments.

The present study also revealed that the ECOHIS score was mainly composed of parent distress domain, function domain, and pain domain. Remaining three domains, i.e., psychological domains, self-image domain, and family function, domain did not contribute much in it. The ECOHIS responses reported that items related to pain, irritation, difficulty in eating some foods, and difficulty to drink hot or cold beverages, felt guilty, feeling of frustration, been upset were the most frequent on the CIS which is in accordance with the study conducted by Albanto et al. ${ }^{16}$

In the present study, the mean ECOHIS score was found to be significantly more among subjects where parents were from the higher income group. Which is in contrast with the studies by Locker et al. ${ }^{12}$ and Albanto et al. ${ }^{16}$ in which low-income families have shown poorer general and oral health than high-income families and considered high family income as a protective factor for the OHRQoL in relation to ECC.

Brushing frequency did not show any impact on OHRQoL children which is in accordance with the study conducted by Nurelhuda et al. ${ }^{29}$ and in contrast with the study conducted by Shaghaghian et al., ${ }^{30}$ who reported that frequency of tooth brushing had a statistically significant impact on OHRQoL of the children.

According to the results of present study, pufa scores could not show any impact on the overall mean ECOHIS score or itemwise. Result of this parameter could not be compared with any other studies because of paucity of the documented data regarding effect of pufa scores and OHRQoL among children.

In the present study, the mean ECOHIS score for the cariesfree subjects was found to be $0.02 \pm 0.52$, for subjects with low severity dental caries was $2.75 \pm 5.72$, and for the subjects with high severity dental caries was found to be $13.5 \pm 4.68$, it was found to be statistically significant. The increase in ECC severity showed an increased negative impact on the quality of life of the child. Thus, the findings of the present study confirm the hypothesis that ECC adversely affects the OHRQoL of preschool children and their families. This is in accordance with the studies conducted by Albanto et al. ${ }^{16}$ and Wong et al. ${ }^{28}$ among preschoolers.

All the items of ECOHIS except item number 9 (avoided talking) showed a significantly higher mean score among children having high severity of dental caries as compared to those who were caries free. Both CIS and FIS were found to be associated with severity of dental caries.

\section{Conclusion}

In the present study, most of the primary caregivers, i.e., 91.9-99.9\%, reported that their child or family "never" experienced such problems. The ECOHIS also needs to be further tested in different populations with known differences in clinical disease to further establish its discriminative properties in clinical populations. Dental disease and its treatment can have a negative influence on the quality of life of young children and their families. The assessment of these influences can help clinicians and researchers in their attempts to improve oral health outcomes for young children.

Why this paper is important to pediatric dentists

- Dental care prevents bacteria from continuing to grow, which may eventually lead to other dental diseases.

- The burden of treating these diseases leads to poor nutrition and together with time taken off school for the children and work for parents, it can be detrimental to the physical and social health of both the children and their parents with $90 \%$ of preschool children being affected and with the disease threatening to affect the well-being of millions of children.

- It is important to better understand why parents feel bad about the dental diseases their children are suffering from and how pediatric dentists can potentially contribute to improve the oral health of the children and OHRQoL in these families.

\section{Authors' Contributions}

Jaggi $A$ and Marya CM conceived and designed the experiments. Jaggi A and Nagpal R organized the data collection. Nagpal R analyzed and interpreted the data. Jaggi A wrote the first draft of the paper. Oberoi S, Kataria S, and Taneja P contributed to scientific input and critically revised the manuscript. The final approval of the published version was given by all authors: Jaggi A, Marya CM, Nagpal R, Oberoi SS, Kataria S, and Taneja P.

\section{ACKNoWledgment}

The authors wish to thank the dental professionals working in Sudha Rustagi College of Dental Science and Research who supported data collection for this study.

\section{References}

1. Petersen $\mathrm{PE}, \mathrm{Ueda} \mathrm{H}$. Oral health in ageing societies: integration of oral health and general health: report of a meeting convened at the WHO Centre for Health Development in Kobe, Japan 2005.

2. Thomas A, Jacob A, et al. Evaluation of the knowledge and attitude of expectant mothers about infant oral health and their oral hygiene practices. J Int Soc Prevent Community Dent 2015;5:400-405. DOI: 10.4103/2231-0762.163405.

3. Sheiham A, Maizels JE, et al. The concept of need in dental care. Int Dent J 1982;32:265-270.

4. Kalra G, Bansal K, et al. Prevalence of Early Childhood Caries and Assessment of its Associated Risk Factors in Preschool Children of Urban Gurgaon, Haryana. IJDS 2011;3:12-16. 
5. Manchanda K, Naganandini S, et al. Oral Health-Related Quality of Life-A changing revolution in dental practice year. J Cranio Max Dis 2014;3:124-132. DOI: 10.4103/2278-9588.138230.

6. Martins J, Unior PA, et al. Impact of early childhood caries on the oral health-related quality of life of preschool children and their parents. Caries Res 2012;47:211-218. DOI: 10.1159/000345534.

7. World Health Organiztion. Oral Health Surveys: Basic methods. 5th ed. Geneva: 2013.

8. Monse B, Heinrich-Weltzien R, et al. PUFA - An index of clinical consequences of untreated dental caries. Community Dent Oral Epidemiol 2010;38:77-82. DOI: 10.1111/j.1600-0528.2009.00514.x.

9. Mohamed N. An investigation of Early Childhood Caries in the lower socioeconomic areas surrounding Tygerberg Oral Health Centre in order to plan a community appropriate intervention strategy. Stellenbosch University. 2014. http://scholar.sun.ac.za.

10. Kaplan RM. The significance of quality of life in health care. Qual Life Res 2003;12:3-16. DOI: 10.1023/A:1023547632545.

11. Rebok G, Riley A, et al. Elementary school-aged children's reports of their health: a cognitive interviewing study. Qual Life Res 2001;10: 59-70. DOI: 10.1023/A:1016693417166.

12. Locker $D$, Jokovic $A$, et al. Family impact of child oral and oro-facial conditions. Community Dent Oral Epidemiol 2002;30:438-448. DOI: 10.1034/j.1600-0528.2002.00015.x.

13. Cremeens J, Eiser C, et al. Characteristics of Health-related Self-report Measures for Children Aged Three to Eight Years: A Review of the Literature. Quality of Life Res 2006;15:739-754. DOI: 10.1007/s11136005-4184-x.

14. Wilson-Genderson $\mathrm{M}$, Broder $\mathrm{H}$, et al. Assessing the impact of oral health on the life quality of children: implications for research and practice. Community Dent Oral Epidemiol 2004;32:81-85. DOI: 10.1111/j.1600-0528.2004.00149.x.

15. Pahel BT, Rozier RG, et al. Parental perceptions of children's oral health:The Early Childhood Oral Health Impact Scale (ECOHIS). Health Qual life outcomes 2007;5:6-12.

16. Albanto J, Carvalho TS, et al. Impact of oral health-related quality of life of preschool children. Community Dent Oral Epidemiol 2011;39:105-114. DOI: 10.1111/j.1600-0528.2010.00580.x.

17. Li S, Veronneau J, et al. Validation of a French language version of the Early Childhood Oral Health Impact Scale (ECOHIS). Health Qual Life Outcomes 2008;6:9. DOI: 10.1186/1477-7525-6-9.
18. Bordoni N, Ciaravino O, et al. Early Childhood Oral Health Impact Scale (ECOHIS). Translation and validation in Spanish language. Acta Odontol Latinoam 2012;25:270-278.

19. Singh S, Vijayakumar N, et al. Prevalence of early childhood caries among 3-5 year old pre-schoolers in schools of Marathahalli, Bangalore. Dent Res J 2012;9:710-714.

20. Zhang $S$, Lo EC, et al. Dental caries status of Bulang preschool children in Southwest China. BMC Oral Health 2014;14:16. DOI: 10.1186/14726831-14-16.

21. Simratvir M, Moghe GA. Evaluation of caries experience in 3-6-year old children, and dental attitudes amongst the caregivers in the Ludhiana city. J Indian Soc Pedod Prev Dent 2009;27:164-169. DOI: 10.4103/0970-4388.57097.

22. Sudha P, Mahejabeen R. Dental caries prevalence among preschool children of Hubli: Dharwad city. J Indian Soc Pedod Prev Dent 2006;24:19-22.

23. Gopal S, Chandrappa V, et al. Prevalence and Predictors of Early Childhood Caries in 3 to 6 year old South Indian Children-A Crosssectional Descriptive Study. Oral Health Prev Dent 2016;14:267-73.

24. Stephen A, Krishnan R, et al. Prevalence of early childhood caries and its risk factors in 18-72 month old children in Salem, Tamil Nadu. J Int Soc Prev Community Dent 2015;5:95-102. DOI: 10.4103/2231-0762.155731.

25. Namal N, Vehit $\mathrm{HE}$, et al. Risk factors for dental caries in Turkish preschool children. J Indian Soc Pedod Prev Dent 2005;23:115-118. DOI: $10.4103 / 0970-4388.16881$

26. Marya CM, Kataria S, et al. A Cross-sectional Study for Assessment of Untreated Dental Caries and Its Consequences among Slumdwelling Children. Int J Clin Pediatr Dent 2017;10:29-33. DOI: 10.5005/ jp-journals-10005-1402.

27. Chawla TA, Singh H. A study of prevalence of dental caries in an urban area of India - Chandigarh. J Ind Dent Assoc 1977;49:231-237.

28. Wong $\mathrm{HM}$, Mcgrath $\mathrm{CP}$, et al. Oral health related quality of life in Hong Kong preschool children. Caries Res 2011;45:370-376. DOI: 10.1159/000330231.

29. Nurelhuda NM, MutazF, et al. Evaluation of oral health-related quality of life among Sudanese school children using Child-OIDP inventory. Health Qual Life Outcomes 2010;8:152-164. DOI: 10.1186/1477-7525-8-152.

30. Shaghaghian S, Bahmani M, et al. Impact of oral hygiene on oral health related quality of life of preschool children. Int J Dent Hyg 2015;13:192-198. DOI: 10.1111/idh.12129. 